\title{
Live endoscopy events (LEEs): European Society of Gastrointestinal Endoscopy Position Statement - Update 2014
}

submitted 18. August 2014 accepted after revision 25. August 2015

\section{Bibliography}

Dol http://dx.doi.org/

10.1055/s-0034-1390705

Published online: 14.10.2014

Endoscopy 2015; 47: 80-84

(c) Georg Thieme Verlag KC

Stuttgart · New York

ISSN 0013-726X

Corresponding author

Mario Dinis-Ribeiro, MD

European Society of

Gastrointestinal Endoscopy

Secretariat: Hamilton

Services $\mathrm{GmbH}$

Landwehr Str. 9

80336 Munich

Germany

Fax: +49-89-907793620

secretariat@esge.com
The European Society of Gastrointestinal Endoscopy (ESGE) is dedicated to improving the quality of gastrointestinal endoscopy through educational activities such as live endoscopy events (LEEs). The primary utility of LEEs is the educational value for the audience, and patients should not expect additional benefit from being treated during a LEE compared to a routine setting. Although there is no evidence that LEEs entail additional risks for patients, neither can possible unknown risks be excluded as the evidence available is limited. Therefore, necessary measures should be taken to assure patient safety. Pa-

\section{Reason for updating existing guidelines $\nabla$}

The European Society of Gastrointestinal Endoscopy (ESGE) aims to improve the quality of gastrointestinal (GI) endoscopy through promoting and organizing educational activities.

GI endoscopy, similarly to surgery, combines medical knowledge and procedural skills to accomplish a standard of care. For this reason, ESGE offers several educational resources, ranging from e-learning platforms and DVDs to hands-on courses using models and to provision of fellowships to allow clinical training under supervision [1 -4]. Among these educational activities, ESGE, like other GI endoscopy societies [5, $6]$, promotes and endorses live endoscopy events (LEEs) as an effective educational tool $[7,8]$.

The main advantages of LEEs are that they demonstrate a real-time approach to a clinical case by experts, and allow the education of a large audience by means of audiovisual technologies.

To address concerns about patient safety, and about the educational benefit of LEEs, ESGE has recognized the need for LEE regulation, and in 2003 provided detailed recommendations for the conduct of LEEs $[7,8]$. tients must be adequately informed that the standard of care will be assured and that their identity will not be revealed. ESGE recommends that an endoscopist not belonging to the hosting unit is named as patient advocate. Clinical indications for the LEE procedures and the educational outputs must be clear and agreed between host and demonstrator teams. ESGE will ensure that in all ESGE-organized LEEs the indications, procedural descriptions, and adverse events will be registered, and that organizers requesting ESGE endorsement can demonstrate such a registry.

ESGE has decided to update these recommendations in 2014 for the following reasons. First, in surgery and cardiovascular medicine, there has been careful reconsideration of live demonstrations for concerns on patient safety; some societies have imposed strict regulations for live events [9-11] and others have banned live procedures altogether [12]. Second, the efficacy and safety of endoscopic procedures in LEEs has now been addressed in a few papers, summarized in Appendix 1, although any definitive conclusion on the LEE risk/benefit ratio is premature [13-15]. Third, there is a lack of dedicated studies addressing the educational efficacy of this method, and of any comparative data regarding alternative educational methods [16]. Fourth, live events present a number of ethical issues, and, fifth, audiovisual and broadcasting technologies are improving rapidly, enabling alternative approaches to LEEs [17-20].

\section{Structure and methods}

\section{$\nabla$}

The Governing Board of ESGE commissioned the Educational and Guideline Committees to update the previous ESGE recommendations on LEEs. A 
working panel was responsible for a literature search (PubMed, April 2014) and preparation of a preliminary draft. This draft was based on the need for complete transparency of the different parties involved in LEEs, and for a clear code of conduct for all these. This draft was then sent for modifications and final approval to the ESGE Governing Board and circulated among ESGE individual members and national societies.

Practical considerations and recommendations for those planning to organize or host an LEE, in collaboration with ESGE or seeking endorsement by ESGE, are given below (see also www. esge.com). ESGE's own organizational basis for LEEs is described in Appendix 2. All the recommendations in this document are compiled in Appendix e3 (available online).

\section{The patient}

$\nabla$

Patient safety and proper care must take precedence over all other considerations. Although theoretically it cannot be excluded that patients may benefit from participating in an LEE (i.e., because of especially careful examination, and additional expertise available from the faculty), as yet no available evidence supports this. Patients should therefore be informed that no additional benefit should be expected from being treated in an LEE as compared with a routine setting. Similarly, although there is no evidence of actual LEE-related risks, the available evidence is still too limited to exclude possible unknown risks. It is mandatory that patients are well informed about the procedure and its features in a LEE. The patient should be informed in advance of the proposal to include them as a case in a live demonstration, so that the patient has the opportunity to discuss and weigh up the advantages and disadvantages. Informed consent for both the procedure and LEE participation is mandatory. Every attempt should be made for patients to be unidentifiable during the event, but patients should be informed that this may be difficult during procedures by mouth. At all times patients should be treated with respect and friendliness.

Patients with severe co-morbidities may not be suitable for LEE demonstrations, because of the higher frequency of prolonged deep sedation in LEE as compared with routine procedures (Appendix 1). However, short procedures with strong indication (i.e. stenting for esophageal cancer) may be considered in this setting. If any severe adverse event occurs, the video transmission must be discontinued immediately and switched to another procedure in another operating suite. Thus, the focus can stay on the optimal medical care for the patient.

- Informed consent. An additional separate written informed consent must be signed for LEE participation. The presence of a third party is recommended. Patients must be informed that they may at any point refuse or withdraw their consent. Patients must not suffer any disadvantage for refusing or withdrawing their permission, and their endoscopic procedures must be performed outside the LEE without significant delay.

\section{Patient advocate}

$\nabla$

ESGE suggests that patients are represented by an endoscopist, the patient advocate, who does not belong to the local organizing committee (LOC) (see below) and who reports to the director of the LOC. This endoscopist should have: (a) extensive experience in endoscopy and training; (b) knowledge of the local languages and of English; and (c) no conflicts of interest with the director of the LOC, local staff or visiting faculty members.

This patient advocate will have responsibilities regarding:

- Patient care, dignity, and anonymity. As an independent advocate for the patient, he/she must intervene and liaise with the director or staff of the LOC if, at any time, any of those patient interests are put at risk by lack of adherence to the ESGE recommendations for LEEs. The final decision by the director of the LOC must be respected by all parties, including the patient advocate.

- Conflict of interest. If the patient advocate perceives a possible personal or financial conflict of interest, for any of the parties involved, that might breach the ESGE recommendations, he/she must liaise with the director of the LOC.

- Post-LEE feedback. The patient advocate must give general feedback to the director of the LOC in a written proforma report; this must include all the potential or actual breaches of the ESGE recommendations or any other action that may have exposed patients to an increased risk related to the LEE.

\section{Faculty: operators and moderators}

$\nabla$

The faculty consists of local and visiting operators and moderators. In general, both operators and moderators should be recognized experts in their own fields and familiar with the relevant equipment, techniques, and devices; they should have experience in training and teaching; and be proficient in English. In principle, ESGE supports the integration of doctors from the local unit into the demonstrator team; this is to avoid undue risk to patients arising from visiting operators' unawareness of specific details or data, and to avoid undue stress for visiting operators.

\section{Operators' responsibilities}

The operator is responsible for:

- Patient care. The operator is the only person responsible for the endoscopic outcome of the procedure. Thus, the operator, together with the local doctors responsible for the patient's care and, preferably with the independent patient advocate, should check each individual case that will be performed, including case history, planned procedures, and possible risk factors. The operators should also be introduced to the rest of the intervention team, including endoscopy nurses and anesthesiologists, and discuss the case with them. If the indication is deemed to be inappropriate, the LOC director should be immediately informed and the case cancelled. No procedure should be done only to demonstrate an endoscopic technique or device. Although the operator should focus primarily on the care of the patient, he/she should also, as needed and feasible, show the equipment used, accessory preparation, and other features that may improve the educational output of the case. The operator must also educate the host team as needed regarding any devices or procedures that require special knowledge.

- Local staff support. Visiting operators are unfamiliar with both the patient case and the endoscopic setting. Local staff must present visiting faculty members with relevant documentation on the patient case. This must be done well ahead of the scheduled procedure.

- Availability of material and staff. Visiting operators must state what material is required for performance of the pre-planned procedure. If the LOC director cannot provide the required 
material, the visiting operator must be allowed to bring their own material to the LEE center without any restriction from the LOC director or sponsoring companies. An exception may occur when specific material is not commercially available. In that situation, either the case or the operator must be changed accordingly. If the visiting operator feels that an accompanying nurse/technician may improve the procedure outcome, the operator must be allowed to bring the nurse/technician to the LEE, and insurance coverage should be extended accordingly. Necessary arrangements for familiarizing the expert with a new device should be made well in advance.

- LEE procedure. LEE operators are expected to carry out only procedures in which they have extensive experience. New techniques, adding a potential clinical benefit for the patient, may be included at an LEE only if the LOC staff has already been trained in them.

- Post-procedure management. Although the LOC director is responsible for the clinical management of the patient, the visiting operator should liaise with the LOC director as needed. Thus, the visiting operator should remain in contact with the local staff until the resolution of the case.

\section{Moderators' responsibilities}

A moderator is responsible for:

- Patient care. Although moderators are not directly included in patient care, they should never expose patients to risk. Thus, excessive prolongation of the procedure because of extended discussions must be avoided. It is desirable to have two moderators, one in the endoscopy room and one in the conference center, so that the operator is not distracted. Moderators or the audience may favor therapeutic strategies that are different from that of the LEE operator. In an extreme situation of different opinions, and if the best care of the patient is at risk, the independent advocate or the LOC director should be informed and should decide on the best interests of the patient.

- Educational benefit. Moderators must reinforce the educational message of LEE events. A description of the individual patient's history and previous examinations, along with teaching points, should be delivered by the local staff before the start of each procedure. During the procedure, the moderators must interact to underline the educational and training points of the procedure. The moderators are also expected to interact with a multidisciplinary panel and the audience to provide further perspectives and clarification.

\section{Organizing host and local organizing committee (LOC) $\nabla$}

\section{The organizing host}

Hosting a live endoscopic live demonstration may have a significant positive impact on the reputation of an institution or department. Competence and effectiveness in GI endoscopy may potentially be demonstrated to a wider audience. Nevertheless, organizing a successful event requires substantial work. It is extremely important that the organizing team functions well. All of the workflow, from patient selection to post-procedural surveillance should be well structured and organized to enable a smooth live demonstration with no delays. More personnel are required than during routine procedures. Insurance coverage of treated patients and host faculty members should be clarified with local authorities.
In general, host units should be high volume centers with sufficient facilities to run three or more procedures in parallel. There must be enough room in each of the endoscopy suites, including space for technicians and technical equipment. The possibility for high quality (high definition [HD]) audiovisual transmission should be clarified in advance. Audiovisual technicians should be able to simultaneously transmit various video sources (showing the operating endoscopist, the endoscopic image, fluoroscopic image, etc), and the moderators should be able to switch from one room to another. Alternatively, recorded cases or lectures may be used if no room is ready.

Attempts should be made to record and store the complete live demonstration for e-learning libraries. It is also recommended to collect data on each patient's outcome after their procedures.

\section{The local organizing committee (LOC)}

The local organizing committee consists of:

(i) the local director

(ii) local staff (physicians/nurses/technicians/anesthesiologists, etc.)

The LOC director is responsible for:

- Patient care. The clinical management of the patient is the responsibility of the LOC director, and possibly also of the anesthesiologist in charge of the patient, within the area of competence of each clinician. The LOC director - also with the support of the patient advocate - must interrupt the LEE procedure if he/she feels that the LEE is posing an additional risk to patient safety. In the case of endoscopy-related adverse events, the LOC director is responsible for managing such adverse events in liaison with the operator.

- Definition of educational goals. This is done in liaison with the ESGE-LEE educational committee. Any liaison with industry on the definition of such goals is prohibited, to prevent influence on the selection of patients and procedures.

- Selection of faculty members. Only experts with adequate skills and experience in endoscopic training should be included (see above).

- Disclosure of conflict of interest. Local staff, visiting faculty members, and companies involved must disclose all their personal and financial conflicts of interests before the LEE. If any of these conflicts jeopardizes patient safety, the person(s) or companies must be excluded from the LEE.

- Availability of material for LEE procedures. The LOC director officially requests the visiting operators to provide the list of material needed to do pre-specified procedures during the LEE (see above), and requests such material from the corresponding manufacturers. If material is not available, the visiting operators must be informed, and appropriate consequent action must be taken.

- Availability of additional staff for LEE procedures. The LOC director officially asks the visiting operators to specify what staff are needed to do pre-specified procedures in the LEE. Visiting operators may require additional medical assistants or nurses from their own centers to reduce the risks associated with the lack of familiarity with the LEE environment (see above).

- Selection of procedures. These must relate to the educational goals. No procedure is permitted that does not provide an educational benefit. Only procedures that are considered 'standard' within the center should be performed. Techniques not routinely performed should be prohibited, because of possible risk before, during, or after the procedure. 
- Presence of medical personnel within the LEE endoscopy room. Only the health operators actually needed for patient care and educational purposes, including the patient advocate, should be allowed in the LEE room.

- Post-procedure management. All LEE patients must be visited on the day of the LEE. In the case of adverse events, the LOC director is responsible for clinical management. He/she must also regularly inform the visiting faculty members about management of adverse events.

- Post-LEE feedback. Data on 30-day morbidity and mortality for all patients treated within ESGE-organized or ESGE-endorsed LEEs must be documented in the ESGE registry. Any breach of the ESGE recommendations must also be communicated to ESGE to prevent future repetitions.

- Industry relationships. Companies may be asked to provide the material and financial funding necessary to run the LEE, but must not interfere with its educational goals nor with the actual demonstration of the provided material.

The local staff are responsible for:

- Patient care. When the LOC director is absent, a local endoscopist acts as the representative of the LOC director.

- Patient selection. LEEs have been clearly associated with a higher rate of deep sedation and a longer procedure (Appendix 1). Moreover, an LEE does not represent the most suitable setting for high risk patients, since the educational purposes may distract the operator. Thus adequate sedation should be prepared and, as with all procedures, any risks should be anticipated.

- Assistance to visiting faculty members. Visiting operators are unfamiliar with both the patient case and the endoscopic setting. Local staff must present the visiting faculty with all the documentation on the patient case, including clinical, biochemical, radiological, and other documentation when useful. This must be done at least 3 hours before the scheduled procedure. During LEEs, local staff must support the visiting operator providing medical and nonmedical assistance.

- Case summary and educational goals. To maximize the educational benefit, the broadcast of each LEE case must be associated with a slide presentation of the case history. The last slide(s) must list the educational points of the LEE case.

\section{Medical industry}

$\nabla$

The industry partners supply technical equipment and necessary supporting manpower for the LEE in close association with the faculty and local company representatives. Representatives from the involved companies liaise with the local organizers and ESGE co-director (if there is one) throughout the entirety of the planning and conduct of the course. Industry representatives provide training for local staff regarding the use of devices considered for use during the LEE. Industry representatives must never be directly involved in patient care or assistance during procedures, but remain available for rapid access to equipment and accessories. Industry representatives must never approach co-directors, technicians, assistant personnel, or faculty members to highlight a certain device, feature, etc. without any educational or clinical meaning. When appropriate for patient care, endoscopes and accessories used during workshop should be those of the selected industry partners. This does not exclude the use of other equipment if required for specific patient care.

\section{Conclusion}

Live endoscopic demonstrations are an important component in teaching state-of-the-art practice in endoscopy. Despite the burden and costs involved in LEE, as well as the considerable pressure on all parties involved, patients must never be placed at risk on account of inappropriate selection, endoscopic treatment, or deviation from the highest standards of care.

In principle, ESGE supports courses and events that include live demonstrations, if prepared and conducted in accordance with this Position Paper. In order to improve the efficacy of LEEs as educational activities and to assure patient safety, ESGE will actively assess outcomes during ESGE live events to form a basis for revisiting these recommendations.

Appendix 1: Studies on the efficacy and safety of live endoscopic events (LEEs).

\begin{tabular}{|c|c|c|c|c|c|c|c|}
\hline $\begin{array}{l}\text { Study first } \\
\text { author }\end{array}$ & Country & LEE period & Patients, n & Technique & Comparator & Efficacy & Safety \\
\hline Schmit [13] & Belgium & $1991-2002$ & 168 & ERCP & $\begin{array}{l}\text { Indication-matched } \\
\text { patients }\end{array}$ & $\begin{array}{l}\text { Trend for lower efficacy } \\
\text { in LEE patients (not } \\
\text { statistically significant) }\end{array}$ & $\begin{array}{l}\text { More general anesthe- } \\
\text { sia in LEE patients. } \\
\text { No difference in } \\
\text { adverse events rate }\end{array}$ \\
\hline Liao [15] & China & $2002-2007$ & 406 & ERCP & $\begin{array}{l}\text { Indication/age/ } \\
\text { gender-matched } \\
\text { patients }\end{array}$ & $\begin{array}{l}\text { Lower success for LEE } \\
\text { ERCP }\end{array}$ & $\begin{array}{l}\text { No difference in } \\
\text { adverse events rate }\end{array}$ \\
\hline Ridtitid [14] & Thailand & $2004-2011$ & 82 & ERCP & $\begin{array}{l}\text { Indication/gender- } \\
\text { matched patients }\end{array}$ & $\begin{array}{l}\text { Lower success for over- } \\
\text { all and complex LEE } \\
\text { ERCP }\end{array}$ & $\begin{array}{l}\text { No difference in ad- } \\
\text { verse events rate and } \\
\text { duration of ERCP }\end{array}$ \\
\hline
\end{tabular}

ERCP, endoscopic retrograde cholangiopancreatography 


\section{Appendix 2}

The ESGE-LEE Working Group will be responsible for:

- Planning of LEEs directly organized by ESGE

- Approval of LEEs endorsed by ESGE. This includes careful assessment of the organizational facilities of the LEE center, including local endoscopic, clinical, and surgical competence

- Planning or approval, respectively, of the educational targets of LEEs organized or endorsed by ESGE. The Working Group may require integration or modification of the educational targets in agreement with the local organizer

- Planning or approval, respectively, of the agenda of LEEs organized or endorsed by ESGE. The Working Group may require integration or modifications of the agenda in agreement with the local organizer

- Providing additional material, such as DVDs, when this is considered useful for educational purposes

- Proposal or approval of the local organizing committee, patient advocate, and faculty of LEEs, respectively organized or endorsed by ESGE

- Proposal of an ESGE course co-director (i.e., nonlocal) for ESGE-organized LEEs, to be approved by the ESGE Governing Board

- Assessment of compliance of all the involved parties with the ESGE recommendations for LEEs

- Assessment of all the disclosures of conflict of interest from participating parties (i.e., local organizer, faculty, industry)

- Collection, in a registry, of predefined outcomes including 30-day morbidity and mortality, from LEEs organized or endorsed by ESGE

- Periodic reporting to the Governing Board of the outcomes of LEEs organized or endorsed by ESGE

- Preparation of the documentation required by the ESGE recommendations, including the additional informed consent for patients and the disclosure forms for all the parties involved in the LEE

- The LEE Working Group on behalf of the ESGE Governing Board can at any stage decide to suspend or withdraw ESGE participation in an LEE or endorsement of an LEE, if they perceive a breach of the ESGE recommendations for LEEs or any other situation that may pose a risk to patient safety or on the achievement of educational targets.
Competing interests: None

\section{References}

1 Walsh CM, Sherlock ME, Ling SC et al. Virtual reality simulation training for health professions trainees in gastrointestinal endoscopy. Cochrane Database Syst Rev 2012; 6: CD008237

2 Parra-Blanco A, Gonzalez N, Gonzalez R et al. Animal models for endoscopic training: do we really need them? Endoscopy 2013; 45: $478-$ 484

3 Itoi T, Gotoda T, Baron TH et al. Creation of simulated papillae for endoscopic sphincterotomy and papillectomy training by using in vivo and ex vivo pig model (with videos). Gastrointest Endosc 2013; 77: 793 800

4 Yoshida N, Yagi N, Inada $Y$ et al. Possibility of ex vivo animal training model for colorectal endoscopic submucosal dissection. Int J Colorectal Dis 2013; 28: 49-56

5 Loren DE, Azar R, Charles RJ et al. Updated guidelines for live endoscopy demonstrations. Gastrointest Endosc 2010; 71: 1105-1107

6 Carr-Locke DL, Gostout CJ, Van Dam J. A guideline for live endoscopy courses: an ASGE White Paper. Gastrointest Endosc 2001; 53: 685688

7 Kruse A, Beilenhoff U, Axon AT. ESGE/ESGENA Guideline for live demonstration courses. Endoscopy 2003; 35: 781 - 84

8 Deviere J, Ponchon T, Beilenhoff $U$ et al. Recommendations of the ESGE workshop on Ethical-Legal Issues Concerning Live Demonstrations in Digestive Endoscopy. First European Symposium on Ethics in Gastroenterology and Digestive Endoscopy, Kos, Greece, June 2003. Endoscopy 2003; 35: 765-767

9 Dehmer GJ, Douglas JSJr, Abizaid A et al. SCAI/ACCF/HRS/ESC/SOLACI/ APSIC statement on the use of live case demonstrations at cardiology meetings: assessments of the past and standards for the future. J Am Coll Cardiol 2010; 56: 1267-1282

10 Dehmer GJ. A Code of Conduct is published for live case demonstrations. Eur Heart J 2011; 32: 777 - 778

11 Artibani $W$, Ficarra $V$, Challacombe BJ et al. EAU policy on live surgery events. Eur Urol 2014; 66: 88-97

12 Sade RM. Broadcast of surgical procedures as a teaching instrument in cardiothoracic surgery. Ann Thorac Surg 2008; 86: 357-361

13 Schmit A, Lazaraki G, Hittelet A et al. Complications of endoscopic retrograde cholangiopancreatography during live endoscopy workshop demonstrations. Endoscopy 2005; 37: 695-699

14 Ridtitid $W$, Rerknimitr $R$, Treeprasertsuk $S$ et al. Outcome of endoscopic retrograde cholangiopancreatography during live endoscopy demonstrations. Surg Endosc 2012; 26: 1931 - 1938

15 Liao Z, Li ZS, Leung JW et al. How safe and successful are live demonstrations of therapeutic ERCP? A large multicenter study Am J Gastroenterol 2009; 104: 47 -52

16 Murphy DG. Let the games begin (with EAU approval). Eur Urol 2014; 66: $98-100$

17 Shimizu S, Itaba S, Yada S et al. Significance of telemedicine for video image transmission of endoscopic retrograde cholangiopancreatography and endoscopic ultrasonography procedures. J Hepatobiliary Pancreat Sci 2011; 18: 366-374

18 Rabenstein T, Maiss J, Naegele-Jackson $S$ et al. Tele-endoscopy: influence of data compression, bandwidth and simulated impairments on the usability of real-time digital video endoscopy transmissions for medical diagnoses. Endoscopy 2002; 34: 703-710

19 Lee SP, Lee HL, Hahm JS et al. International live endoscopic multichannel demonstration using superfast broadband internet connections. Clin Endosc 2012; 45: 73-77

20 Huang KJ, Qiu ZJ, Fu CY et al. Uncompressed video image transmission of laparoscopic or endoscopic surgery for telemedicine. Telemed J E Health 2008; 14: 479-485

\section{Appendix e3}

online content viewable at: www.thieme-connect.de 